\title{
Article \\ In Silico Evaluation of Natural Compounds for an Acidic Extracellular Environment in Human Breast Cancer
}

\author{
YoungJoon Park ${ }^{1}$, Jaekwang Jeong ${ }^{2}$, Shin Seong ${ }^{3}$ and Wonnam Kim ${ }^{1, *}$ \\ 1 Cnh Center for Cancer Research, Cnh Corporation, Gangnam-gu, Seoul 06154, Korea; yjparkcb@cnhgroup.kr \\ 2 Section of Endocrinology and Metabolism, Department of Internal Medicine, \\ Yale University School of Medicine, New Haven, CT 06519, USA; jaekwang.jeong@yale.edu \\ 3 Soram Korean Medicine Hospital, Gangnam-gu, Seoul 06154, Korea; ss9335@soramhospital.kr \\ * Correspondence: eb75lab@cnhgroup.kr
}

check for updates

Citation: Park, Y.; Jeong, J.; Seong, S.; Kim, W. In Silico Evaluation of Natural Compounds for an Acidic Extracellular Environment in Human Breast Cancer. Cells 2021, 10, 2673. https://doi.org/10.3390/cells10102673

Academic Editor:

Natália Cruz-Martins

Received: 7 September 2021

Accepted: 3 October 2021

Published: 6 October 2021

Publisher's Note: MDPI stays neutral with regard to jurisdictional claims in published maps and institutional affiliations.

Copyright: (c) 2021 by the authors. Licensee MDPI, Basel, Switzerland. This article is an open access article distributed under the terms and conditions of the Creative Commons Attribution (CC BY) license (https:// creativecommons.org/licenses/by/ $4.0 /)$.

\begin{abstract}
The survival rates for breast cancer (BC) have improved in recent years, but resistance, metastasis, and recurrence still remain major therapeutic challenges for $\mathrm{BC}$. The acidic tumor microenvironment (TME) has attracted attention because of its association with tumorigenesis, metastasis, drug resistance, and immune surveillance. In this study, we evaluated natural compounds from traditional herbal medicine used to treat cancer that selectively target genes regulated by extracellular acidosis. We integrated four transcriptomic data including BC prognostic data from The Cancer Genome Atlas database, gene expression profiles of MCF-7 cells treated with 102 natural compounds, patterns of gene profiles by acidic condition, and single-cell RNA-sequencing from BC patient samples. Bruceine D (BD) was predicted as having the highest therapeutic potential, having an information gain (IG) score of 0.24 , to regulate reprogrammed genes driven by acidosis affecting the survival of BC patients. BD showed the highest IG on EMT (IG score: 0.11) and invasion (IG score: 0.1) compared to the other phenotypes with the CancerSEA database. BD also demonstrated therapeutic potential by interfering with the tumor cell-TME interactions by reducing the amyloid beta precursor protein and CD44 expression. Therefore, BD is a potential candidate to target the acidic TME induced metastatic process in BC.
\end{abstract}

Keywords: acidic tumor microenvironment; breast cancer; natural compound; Bruceine D

\section{Introduction}

In 2020, breast cancer (BC) was the most diagnosed cancer at $24.5 \%$ and was the leading cause of death at $15.5 \%$ among women with cancer [1]. Advances in surgical techniques, radiation therapy, and systemic therapies for $\mathrm{BC}$ contributed to an increase in the 5-year relative survival rate [2,3]. Although BC mortality has continued to improve over the past decades, radiation resistance, drug resistance, and metastatic recurrence still remain major therapeutic challenges for BC [4-6]. Solid tumors produce and export excessive levels of lactic acid due to reprogrammed cancer cell metabolism, and when combined with poor vascular perfusion, it eventually leads to an acidic extracellular $\mathrm{pH}$ $\left(\mathrm{pH}_{\mathrm{e}}\right)$ microenvironment $[7,8]$. The adaptation of cancer cells to acidic $\mathrm{pH}_{\mathrm{e}}$ within the tumor microenvironment (TME) is an important factor in increasing tumor aggressiveness such as invasion and metastasis [9-12]. In acidic regions, tumor cells perform niche engineering that results in extracellular matrix degradation, normal cell death, and local invasiveness $[13,14]$. Tumors with higher metastatic potential showed lower $\mathrm{pH}$ values, dispersedly, in peritumoral regions [15]. Additionally, distant metastasis was associated with enhanced tumor acidity [16]. In BC, exposure to acidic $\mathrm{pH}_{\mathrm{e}}$ increased cell migration and drug resistance in MCF-7 cells [17]. Drug-resistant MCF-7 cells showed lowered $\mathrm{pH}_{\mathrm{e}}$ compared to parent BC cells [18]. Comparison between metastatic 4T1 and less metastatic TUBO cells showed that $\mathrm{pH}_{\mathrm{e}}$ correlated with distant lung metastasis [19]. 
Traditional herbal medicine has long been used to treat cancer, as some herbs contain natural compounds with anticancer effects that target proliferation, angiogenesis, metastasis, and apoptosis [20]. Natural compounds, such as epigallocatechin gallate, curcumin, berberine, artemisinins, ginsenosides, and silibinin, have been reported to regulate autophagy, drug resistance, immunity balance, and chemosensitization in vitro and in vivo [20]. In this study, we analyzed the transcriptomic expression patterns of genes by acidic condition, the BC prognostic data from The Cancer Genome Atlas (TCGA) database, and the gene expression profiles of MCF-7 cells treated with 102 natural compounds from herbal medicine (Figure 1). Moreover, we predicted potential cancer-associated pathways that could be improved by compounds with therapeutic potential for acidic $\mathrm{pH}_{\mathrm{e}}$. Finally, we investigated how compounds would affect receptor-ligand interactions in the TME using single-cell sequencing of BC patient samples (Figure 1).

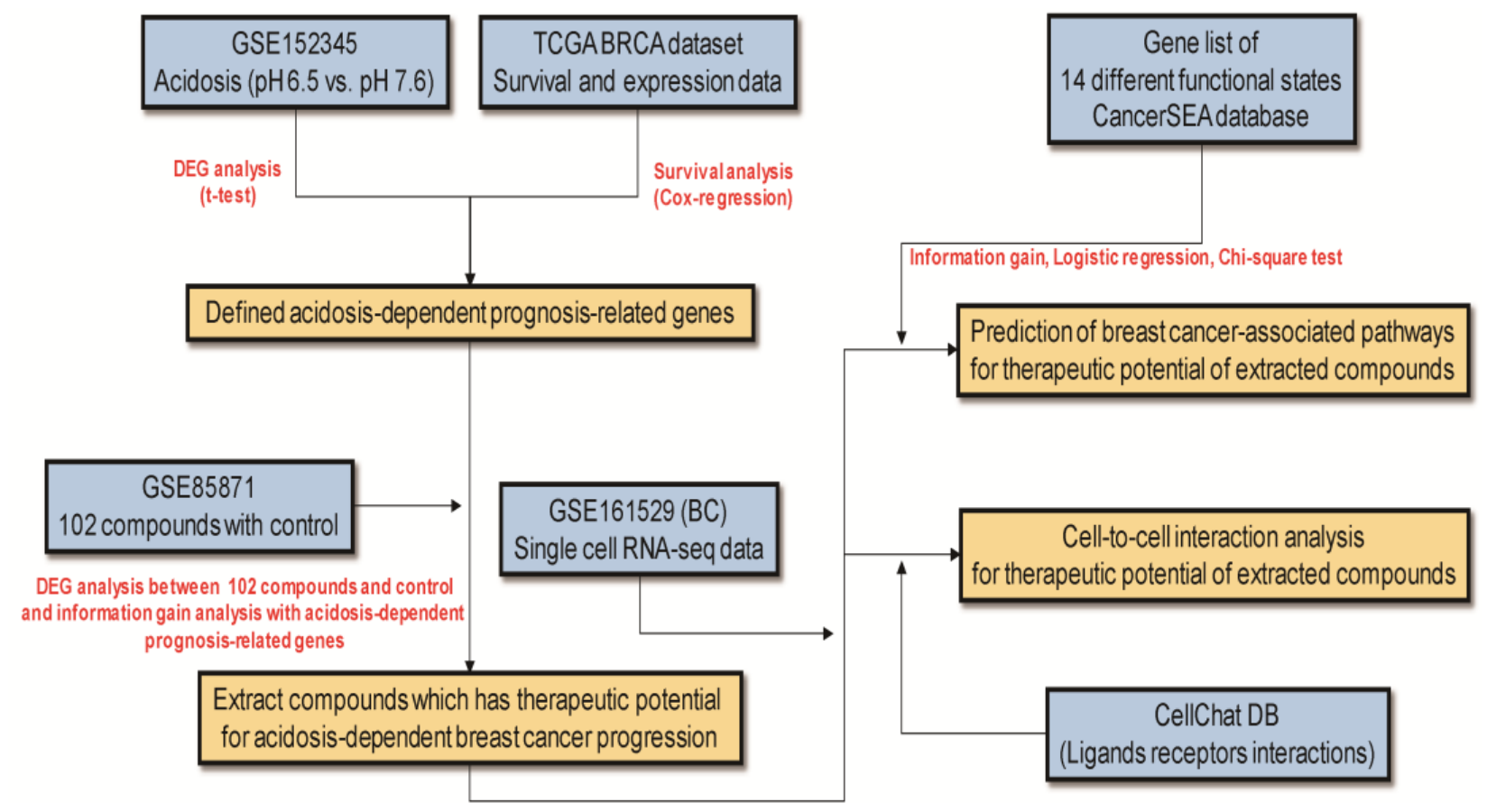

Figure 1. Workflow.

2. Materials and Methods

\subsection{Data Collection}

We downloaded GSE152345 transcriptomic (Illumina HiSeq platform) and survival data of a BC database from Xena TCGA (https: / / xenabrowser.net/hub/, accessed on 27 May 2021). The GSE152345 with a previous study contains whole gene expression levels through high-throughput sequencing with BGISEQ-500 between $\mathrm{pH} 6.5$ and $\mathrm{pH} 7.6$ conditions of the MCF-7 cell line [21]. In addition, we downloaded GSE85871, which contains gene expression profiles of the MCF-7 cell line microarray (Affymetrix human genome U133A 2.0 array) treated with 102 traditional Chinese medicine-related compounds [22]. The gene list with 14 different functional states of tumor cells was downloaded from CancerSEA (http://biocc.hrbmu.edu.cn/CancerSEA/home.jsp, accessed on 10 August 2021) [23]. Finally, we downloaded GSE161529, which contains single-cell sequencing data of tissues from each $\mathrm{ER}^{+}, \mathrm{HER}^{+}$, and triple-negative (TN) BC patient [24].

\subsection{Data Processing}

GSE152345, which contains expression profiles between acidic ( $\mathrm{pH}$ 6.5) and normal ( $\mathrm{pH}$ 7.6) conditions within the MCF-7 BC luminal type, was normalized with the DESeq2 package of R (https:/ / bioconductor.org/packages/release/bioc/html/DESeq2.html, ac- 
cessed on 24 May 2021) and transformed $\log 2(x+1)$ [25]. GSE85871 was downloaded by the GEOquery package of $R$, and duplicated gene symbols were matched according to probe IDs.

\subsection{Acidosis-Dependent Prognosis-Related Genes}

To analyze acidosis-dependent prognosis-related genes, we performed survival analysis with Cox-regression and a t-test for extracting differential expressed genes with TCGA BC and GSE152345 data, respectively. After that, genes that were commonly significant in both analyses were classified into 4 types according to hazard ratio and fold change. The 4 types were risk effect to prognosis and up-regulated in acidic condition (RU), protective effect to prognosis and up-regulated in acidic condition (PU), risk effect to prognosis and down-regulated in acidic condition (RD), and protective effect to prognosis and downregulated in acidic condition (PD).

2.4. Selection Method to Identify Compounds with Therapeutic Potential against Acidosis-Dependent Prognosis-Related Genes

Information gain (IG) was considered as an evaluation parameter to select compounds with therapeutic potential in association with expression patterns of the acidosis-dependent prognosis-related genes. According to the fold change value 0, among the up- or downregulation genes, the proportion of RU or PD was calculated based on Shannon's entropy, and the IG score was calculated.

Let us assume probability $(P)$ and $i$ contain a number of RU ( $r u)$ and PD $(p d)$; therefore, Shannon's entropy was calculated as follows:

$$
\text { Entropy }=-\sum_{i=\{r u, p d\}} P(i) \cdot \log _{2} P(i)
$$

Let us assume $\mathrm{T}$ as the population of targets such as RU or PD before splitting according to the fold change 0 , and $s$ contains up-regulated $(u)$ and down-regulated $(d)$. The IG of each compound was calculated as follows:

$$
I G(T, X)=\operatorname{Entropy}(T)-\sum_{s=\{u, d\}} \frac{s}{T} \cdot \operatorname{Entropy}(s)
$$

\subsection{Evaluation of Compound Effect on 14 Different Functional States from CancerSEA Database}

We performed logistic regression and calculated IG values between those up- or downregulated by the compound treated group and directions such as positive or negative against 14 different functional states from the CancerSEA database, including angiogenesis, apoptosis, DNA damage, DNA repair, epithelial mesenchymal transition (EMT), invasion, differentiation, proliferation, cell cycle, metastasis, hypoxia, stemness, inflammation, and quiescence. The IG was obtained by the calculation formula described above.

Let us assume probability $(P)$ and $i$ contain a number of positives $(p)$ and negatives correlated $(n)$ with each 14 different functional states; the Shannon's entropy was calculated as follows:

$$
\text { Entropy }=-\sum_{i=\{p, n\}} P(i) \cdot \log _{2} P(i)
$$

Let us assume the $T$ as a population of the targets such as RU or PD before splitting according to the fold change 0 , where $s$ contains up-regulated $(u)$ and down-regulated $(d)$. The IG of each compound is calculated as follows:

$$
I G(T, X)=\operatorname{Entropy}(T)-\sum_{s=\{u, d\}} \frac{s}{T} \cdot \operatorname{Entropy}(s)
$$


The logistic regression was performed with directions for each 14 different functional states as a dependent variable and up- and down-regulated in compound treated states as an independent variable.

\subsection{Single-Cell Sequencing Analysis}

We downloaded 3 single-cell RNA sequencing (scRNA-seq) data of ER ${ }^{+}$(GSM4909299, GSM4909307, and GSM4909315), HER2+ (GSM4909289, GSM4909290, and GSM4909294), and TN (GSM4909281, GSM4909282, and GSM4909288), each from GSE161529. Tumor cells in each subtype including $\mathrm{ER}^{+}, \mathrm{HER}^{+}$, and TN were extracted according to their specific markers: KRT5 ${ }^{-}, K R T 18^{+}$, and $E S R 1^{+}\left(\mathrm{ER}^{+}\right) ; K R T 5^{-}, K R T 18^{+}$, and $E R B B 2^{+}\left(\mathrm{HER} 2^{+}\right)$; and $K R T 5^{+}$and $K R T 18^{+}(\mathrm{TN})$. After extracting tumor cells from the single-cell population, we calculated the percentage of cells expressing each marker within the extracted tumor cells. All of the processes were performed by Seurat (https:/ / satijalab.org/seurat/, accessed on 3 August 2021) [26].

\subsection{Cell-to-Cell Interaction Analysis with scRNA-seq}

We downloaded scRNA-seq data from normal (GSM4909262) samples, and ER ${ }^{+}$tumor (GSM4909313) paired samples were downloaded from GSE161529. Clustering and annotation of cell types of normal and $\mathrm{ER}^{+}$tumors were performed by Seurat [26] with default options, and cell-to-cell communication analysis was conducted with the CellChat (http: / / www.cellchat.org/, accessed on 19 August 2021) package of R [27]. The interaction database was retrieved from CellChatDB, which contains a total of 2,021 molecular interactions including paracrine/autocrine (60\%), ECM-related (21\%), and cell-cell contact (19\%) interactions [27].

\subsection{Statistical Analysis}

We performed t-test, Cox-regression, and logistic regression analyses in this study. The threshold of the $p$-value is $<0.05$ with a t-test and Cox-regression without adjusting for multiple comparisons. With logistic regression, we applied Bonferroni corrections for adjusting multiple comparisons. All of the statistical analyses were performed by Rstudio (Version 1.41106) and Python (Version 3.9).

\section{Results}

\subsection{Identification of Acidosis-Dependent Prognosis-Related Genes}

To identify acidosis-dependent prognosis-related genes, a Cox-regression and t-test were performed between acidic ( $\mathrm{pH}$ 6.5) and normal ( $\mathrm{pH}$ 7.6) conditions with GSE152345 based on whole gene expression for the overall survival from TCGA, respectively (Figure 2A, Tables S1 and S2). According to the hazard ratio and fold change, we classified the data into four types such as RU, PU, RD, and PD (Figure 2B). As a result, 2148 (Table S1) and 2328 (Table S2) significant genes were extracted with the Cox-regression for extracting prognosisrelated genes and the t-test to identify differential expressed genes (DEGs), respectively (Figure 2C). Among these significant genes, 307 genes were significant in both statistical analyses (Figure 2C and Table S3). According to the hazard ratio and fold change, 35, 70, 163, and 39 genes were defined as RU, PD, PU, and RD, respectively (Figure 2C).

\subsection{Evaluation of Therapeutic Compounds against an Acidosis-Dependent Manner in BC}

For this study, 102 traditional herbal medicine-related compounds were evaluated against acidic conditions. We focused on RU- or PD-type genes that cause an acidosisrelated risk effect by up-regulating risk genes or down-regulating protective genes, respectively. Among the 102 compounds, Bruceine D (BD) had the highest IG score (0.24) with RU and PD (Figure 3A). Among the 27 up-regulated probes in the BD-treated group, 24 probes were PD type, which indicates a better prognosis and is down-regulated by acidic $(\mathrm{pH}$ 6.5) conditions (PDU) (Figure 3B,C). In addition, among the 15 down-regulated probes in 
the BD-treated group, 10 probes were $\mathrm{RU}$ type, which indicates a poor prognosis and is up-regulated by acidic (pH 6.5) conditions (RUD) (Figure 3B,C).

A

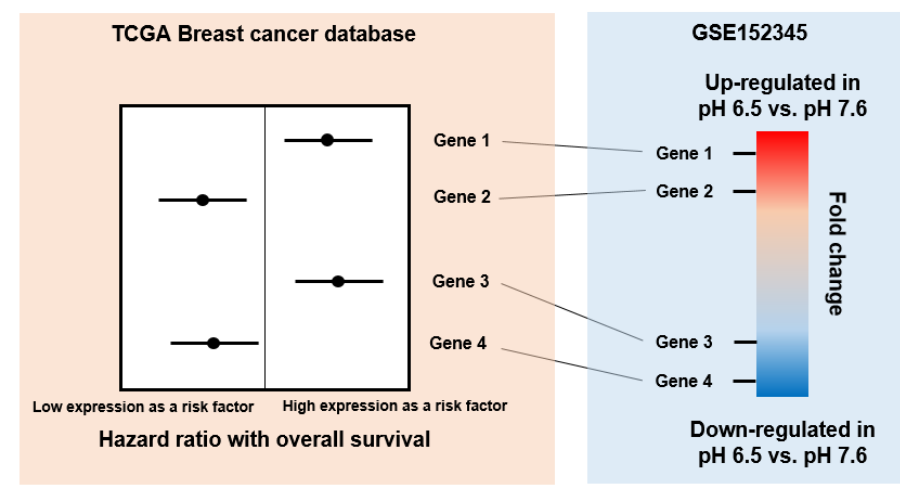

B

\begin{tabular}{lcccc}
\hline & $\begin{array}{c}\text { Prognosis } \\
\text { in TCGA }\end{array}$ & $\begin{array}{c}\text { Acidosis } \\
\text { (GSE152345) }\end{array}$ & $\begin{array}{c}\text { Acidosis-related } \\
\text { phenotype }\end{array}$ & Type \\
\hline \hline Gene 1 & Risk & Up & Risk & RU \\
\hline Gene 2 & Protective & Up & Protective & PU \\
\hline Gene 3 & Risk & Down & Protective & RD \\
\hline Gene 4 & Protective & Down & Risk & PD \\
\hline
\end{tabular}

C

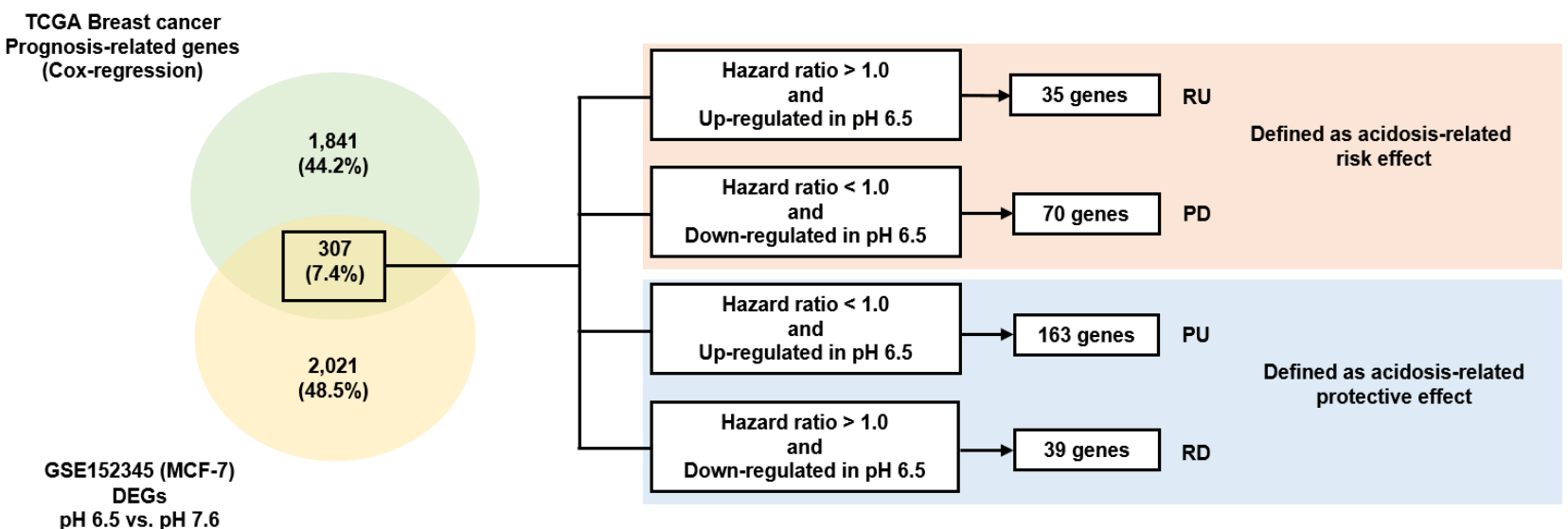

Figure 2. Conception and results of extraction of acidosis-dependent prognostic genes. (A) Conception of linkage between prognostic and acidosis relationship, (B) defined types for acidosis-dependent prognostic genes, and (C) classification of the genes according to the conception and definition.

\subsection{Effect of BD on 14 Different Cancer-Related Functional States with the CancerSEA Database}

To evaluate the effect of BD on tumor cell-related functional states, we downloaded genes and directions with each of the 14 different $\mathrm{BC}$-related functional states including angiogenesis, apoptosis, DNA damage, DNA repair, EMT, invasion, differentiation, proliferation, cell cycle, metastasis, hypoxia, stemness, inflammation, and quiescence (Figure 4). In addition, with the nine total patients, including $\mathrm{ER}^{+}, \mathrm{HER}^{+}$, and TN, cancer cells from a single cell population were segmented (Figures S1-S3), and percentages of positive cells from each of the 14 different tumorigenesis-related functional states were calculated (Figure 4B,D and Figure S4). As a result, EMT and invasion showed higher IG values $>0.1$ compared to the other phenotypes (Figure 4A). Interestingly, the genes that positively correlated with EMT and invasion were highly expressed in the cancer cell populations (Figure 4B,D). Our data showed that BD up-regulated genes had negative correlations with EMT, whereas down-regulated genes had positive correlations with invasion(Figure $4 \mathrm{C}, \mathrm{E}$ ).

\subsection{Effect of BD on Cell-to-Cell Interaction Analysis with scRNA Resolution}

At the single-cell level, we investigated the effect of $\mathrm{BD}$ on ligand-receptor interactions within the TME. The scRNA-seq dataset of the normal and $\mathrm{ER}^{+}$paired sample was used for cell-to-cell interaction analysis. As a result, the $\mathrm{ER}^{+}$cancer sample was clustered with $\mathrm{ER}^{+}$ tumor cells $\left(E S R 1^{+}, K R T 18^{+}\right.$, and $\left.K R T 5^{-}\right), K R T 5^{+} / E P C A M^{+}$double-positive cells, cancer- 
associated fibroblasts (CAFs) $\left(D C N^{+}\right)$, macrophages $\left(C D 68^{+}\right), K R T 5^{+} / E P C A M^{-}$cells, and endothelial cells $\left(V W F^{+}\right)$(Figure $\left.5 \mathrm{~A}, \mathrm{~B}\right)$. In addition, the normal sample was clustered with epithelial cells $\left(K R T 18^{+}\right.$and $\left.E P C A M^{+}\right), K R T 5^{+}$cells $\left(K R T 5^{+}\right)$, and fibroblasts $\left(D C N^{+}\right)$ (Figure S5A,B). Since DEGs analysis for BD was performed in MCF-7 cells, we analyzed the ligand-receptor relationship based on $\mathrm{ER}^{+}$cells (Figure 5C,E). The three ligands including MIF (encodes macrophage migration inhibitory factor), $M D K$ (encodes midkine), and $A P P$ (encodes amyloid precursor protein) were expressed in ER+ cells (Figure 5D) and interacted with receptors including CD74, CXCR4, CD44, SDC4 (encodes syndecan 4), and SDC2 (encodes syndecan 2) expressed in various cell types (Figure 5C and Figure S6A). The two receptors including SDC4 and CD44 were expressed in $\mathrm{ER}^{+}$cells (Figure 5E,F) and interacted with ligands such as the collagen family (COL1A1, COL1A2, COL4A1, COL4A2, COL6A1, COL6A2, and COL6A3), FN1 (Fibronectin 1), the laminin family (LAMC1 and $L A M B 3), M D K, P T N$ (Pleiotrophin), SPP1 (Osteopontin), THBS1 (Thrombospondin 1), THBS2 (Thrombospondin 2), and TNC (Tenascin C) expressed in various cell types (Figure 5E and Figure S6B). Among these ligand-receptor relationships, APP and CD44 were significantly down-regulated by BD in the MCF-7 cell line (Figure 5G). As a ligand, $A P P$ was down-regulated by $\mathrm{BD}$ and interacted with various cell types in $\mathrm{ER}^{+} \mathrm{TME}$ via CD74 (Figure 5C,H). In addition, BD down-regulated CD44, which interacted with several collagen types such as FN1, laminins, and SPP1 (Figure 5E,I). These findings were not detected in normal scRNA-seq data (Figure S5).

A

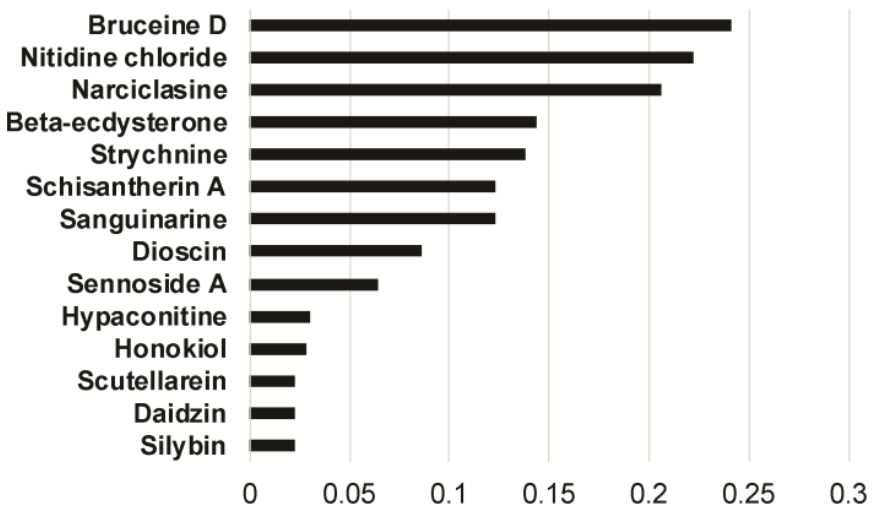

B

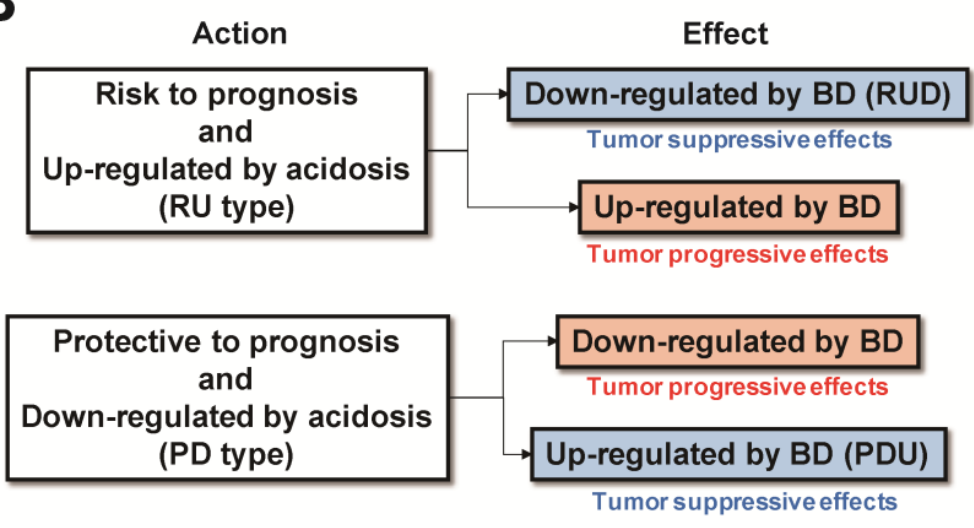

C

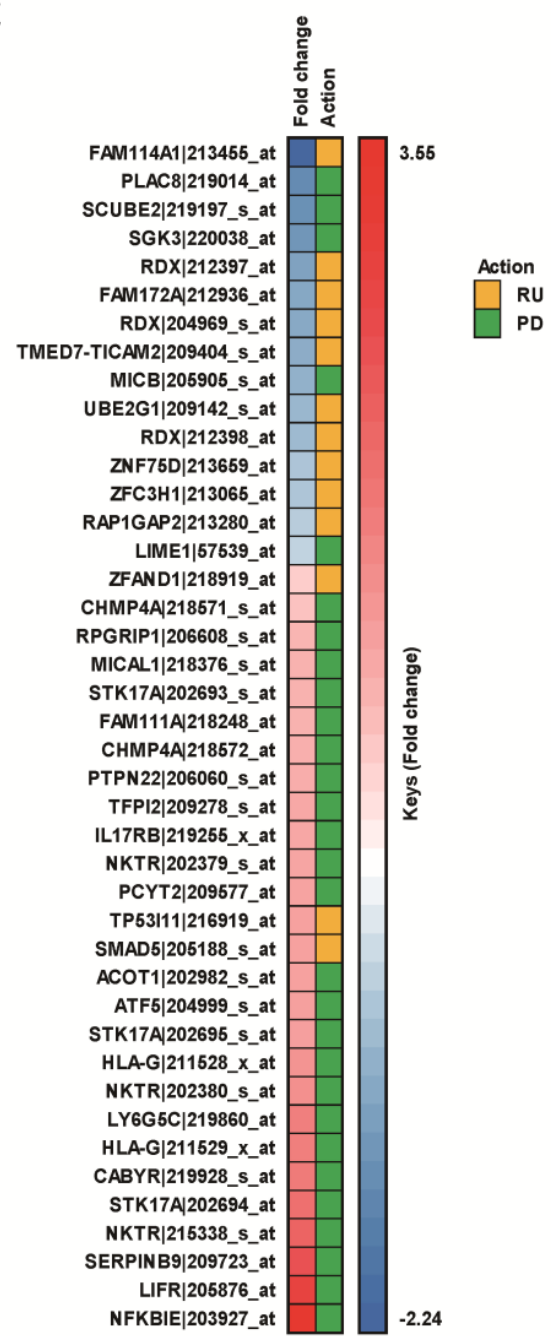

Figure 3. Evaluation of therapeutic potential of the 102 compounds for acidosis-dependent prognostic genes. (A) Evaluation with IG score, (B) defined effect of BD on RU and PD genes, and (C) distribution and patterns of the genes which were affected by BD within acidosis-dependent prognostic genes. 
A

\begin{tabular}{|c|c|c|c|c|c|c|}
\hline \multirow[b]{2}{*}{ Phenotype } & \multirow[b]{2}{*}{ OR } & \multicolumn{2}{|c|}{ Confidence interval } & \multirow[b]{2}{*}{ P-value } & \multirow[b]{2}{*}{ Adj. $P$} & \multirow[b]{2}{*}{ IG } \\
\hline & & Lower & Upper & & & \\
\hline EMT & 0.18 & 0.14 & 0.22 & $5 \times 10^{-13}$ & $7 \times 10^{-12}$ & 0.11 \\
\hline Invasion & 0.19 & 0.16 & 0.22 & $2 \times 10^{-16}$ & $3 \times 10^{-15}$ & 0.1 \\
\hline Apoptosis & 0.24 & 0.2 & 0.29 & $2 \times 10^{-16}$ & $3 \times 10^{-15}$ & 0.07 \\
\hline DNA_damage & 0.25 & 0.21 & 0.28 & $2 \times 10^{-16}$ & $3 \times 10^{-15}$ & 0.06 \\
\hline Hypoxia & 0.3 & 0.26 & 0.36 & $5 \times 10^{-13}$ & $7 \times 10^{-12}$ & 0.06 \\
\hline Metastasis & 0.31 & 0.27 & 0.37 & $8 \times 10^{-14}$ & $1 \times 10^{-12}$ & 0.06 \\
\hline Cell_cycle & 0.31 & 0.27 & 0.36 & $9 \times 10^{-16}$ & $1 \times 10^{-14}$ & 0.06 \\
\hline DNA_repair & 0.31 & 0.28 & 0.35 & $2 \times 10^{-16}$ & $3 \times 10^{-15}$ & 0.05 \\
\hline Angiogenesis & 2.85 & 2.32 & 3.5 & $4 \times 10^{-7}$ & $5 \times 10^{-6}$ & 0.04 \\
\hline Proliferation & 0.36 & 0.29 & 0.44 & $1 \times 10^{-6}$ & $2 \times 10^{-5}$ & 0.04 \\
\hline Stemness & 0.44 & 0.31 & 0.61 & 0.01 & 0.18 & 0.02 \\
\hline Inflammation & 1.96 & 1.72 & 2.23 & $3 \times 10^{-7}$ & $4 \times 10^{-6}$ & 0.02 \\
\hline Quiescence & 1.2 & 1.03 & 1.4 & 0.24 & 1 & 0.001 \\
\hline Differenciation & 0.9 & 0.77 & 1.05 & 0.5 & 1 & $5 \times 10^{-4}$ \\
\hline
\end{tabular}

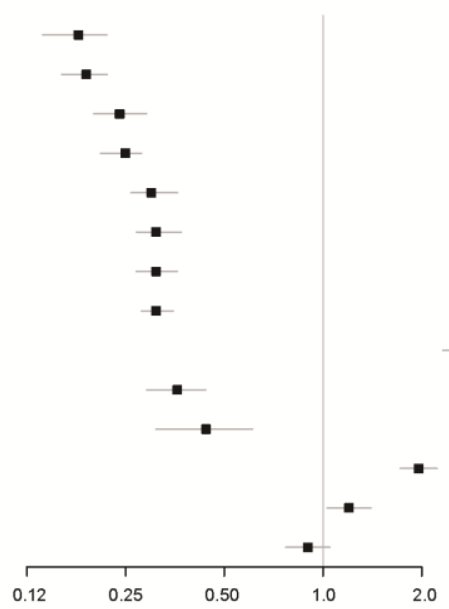

B

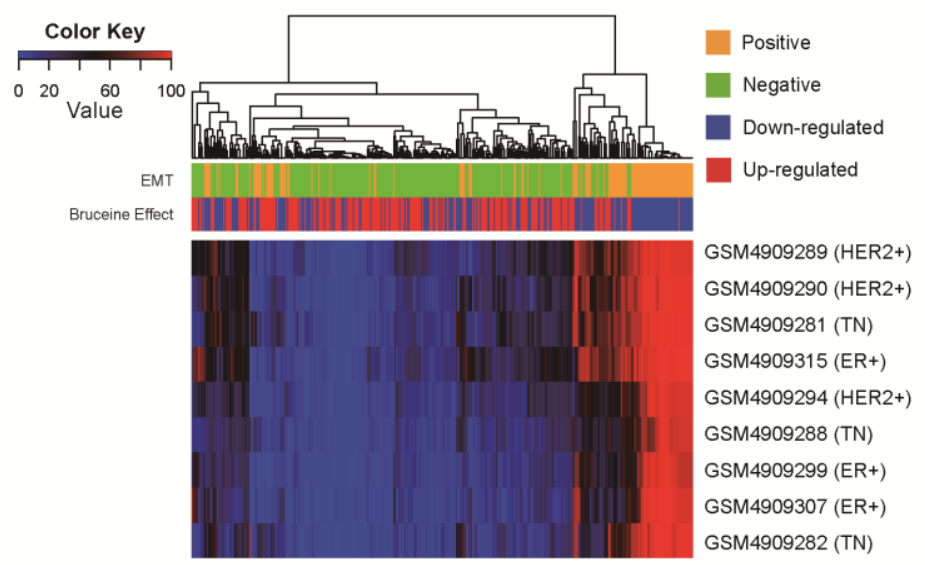

D

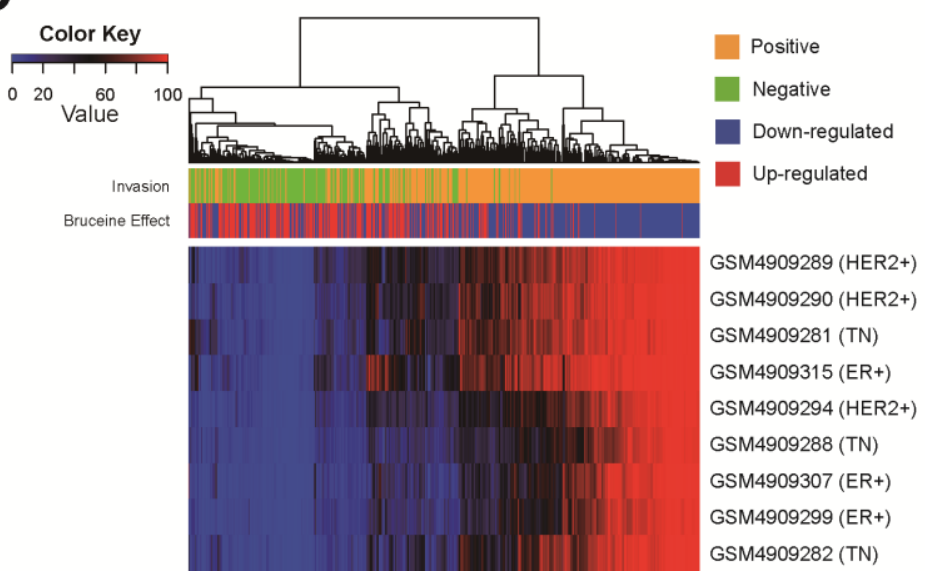

C

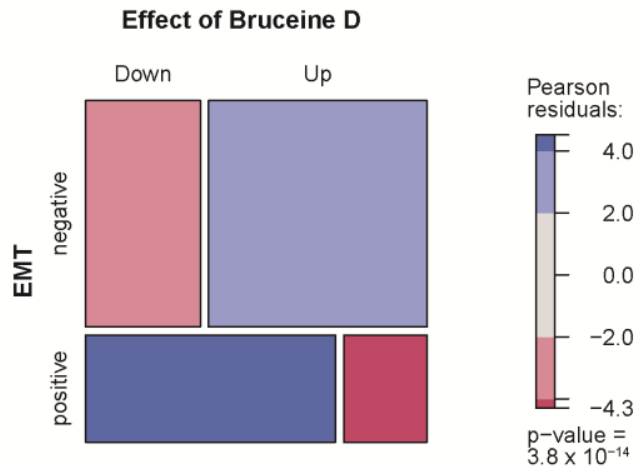

E

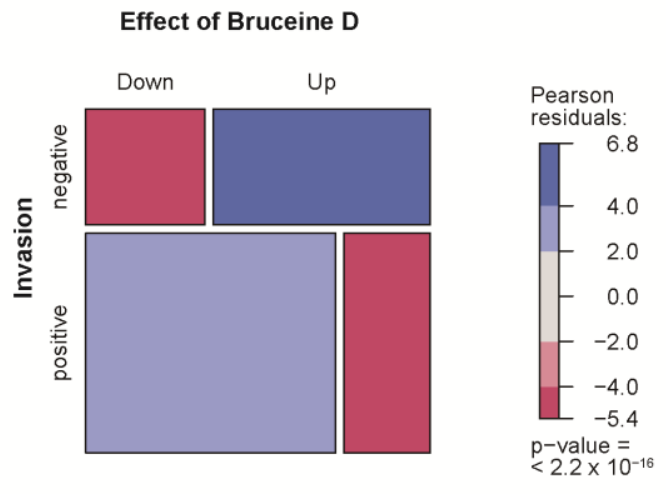

Figure 4. Evaluations with 14 cancer cell-associated functional states. (A) Forest plot and table with logistic regression and IG score. (B) Patterns of EMT associated DEGs with BD genes, and percentages of positive cells within segmented tumor cells from scRNA-seq data. (C) Mosaic plot with Chi-square test and Pearson residuals between EMT and DEGs with BD genes. (D) Patterns of invasion-associated DEGs with BD genes and percentages of positive cells within segmented tumor cells from scRNA-seq data. (E) Mosaic plot with Chi-square test and Pearson residuals between invasion and DEGs with BD genes. 
A
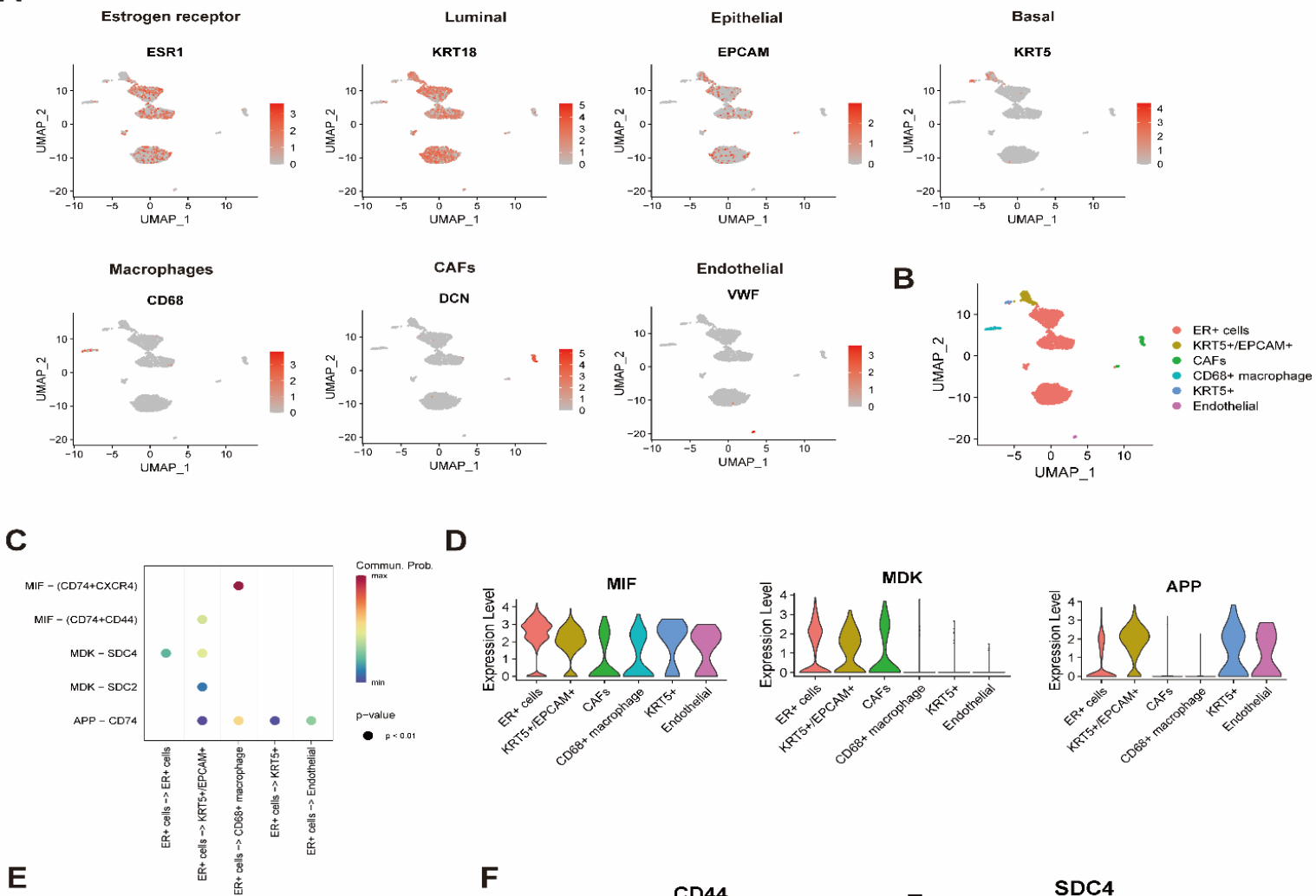

D
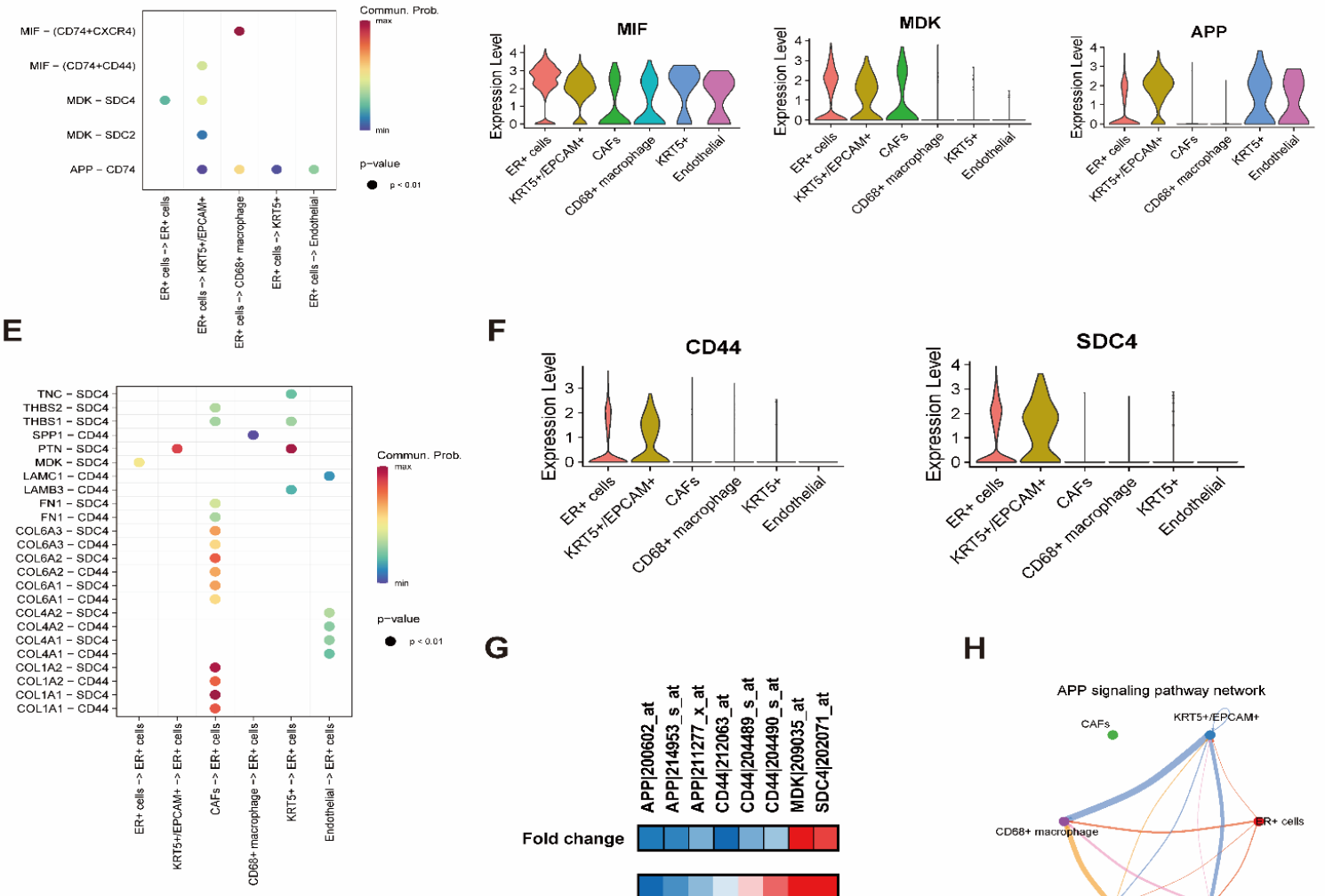

F
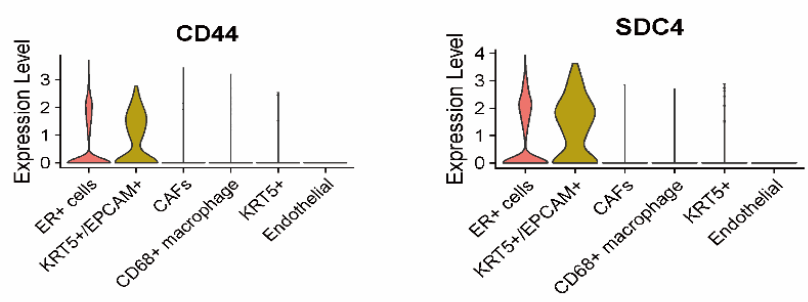

G

H
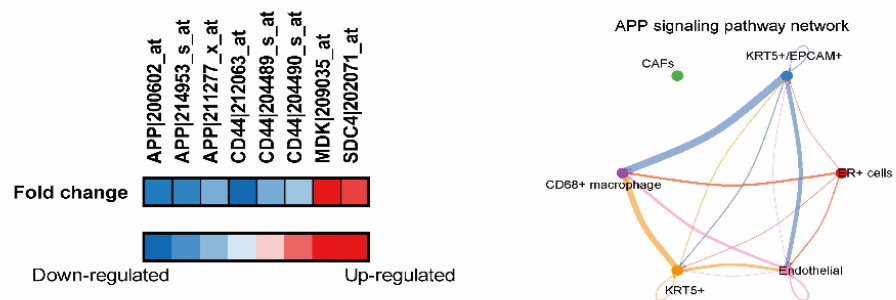

I
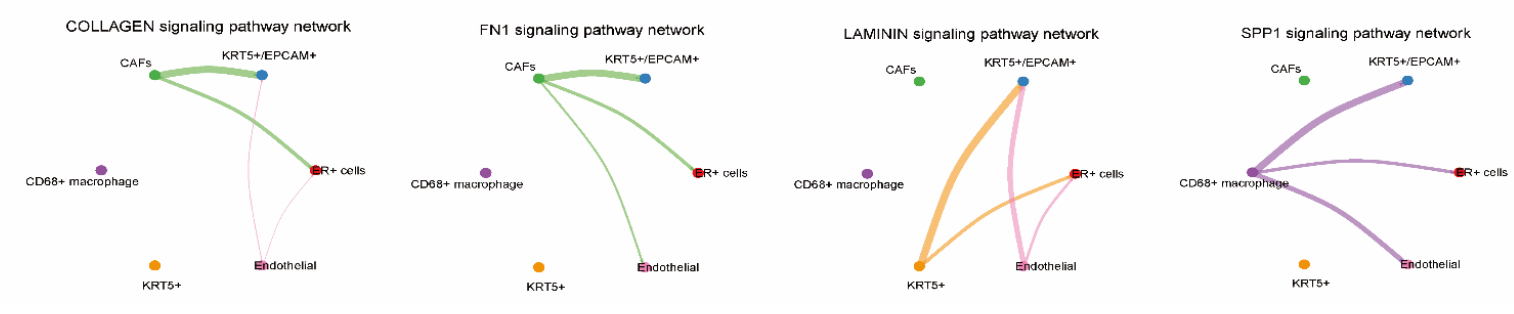

Figure 5. Cell-to-cell interaction analysis with scRNA-seq data from the $\mathrm{ER}^{+}$patient (GSM4909313). (A) Dim plots with markers of each cell type. (B) Dim plot of classified cell types according to the markers of each cell type. (C) Dot plot of ligand-receptor interactions based on ligands expressed in $\mathrm{ER}^{+}$cells. (D) Violin plots of three ligands which were expressed in $\mathrm{ER}^{+}$cells. (E) Dot plot of ligand-receptor interactions based on receptors expressed in ER ER $^{+}$cells. (F) Violin plots of two receptors which were expressed in $\mathrm{ER}^{+}$cells. (G) Heatmap plot of significantly down- or up-regulated genes by BD. (H) Ligand-receptor interaction network based on the APP signaling pathway as a ligand in $\mathrm{ER}^{+}$cells, and (I) ligand-receptor interaction network based on four pathways as ligands on the CD44 receptor in ER ${ }^{+}$cells. 


\section{Discussion}

Solid tumors adapt and survive in acidic TME through $\mathrm{pH}$-regulating proteins such as the sodium/proton exchanger 1 (NHE1), sodium bicarbonate cotransporter (NBC), monocarboxylate transporters (MCT), and carbonic anhydrase $[28,29]$. The acidic TME has received attention due to its association with tumor development, progression, metastasis, drug resistance, and escape from immune surveillance $[28,30]$. The advances in modern technology have increased our understanding of the pharmacology and molecular mechanisms of traditional herbal medicine and its active compounds [31]. Natural compounds exert anti-cancer effects on the TME that consists of tumor cells, stromal cells, immune cells, and non-cellular components such as collagen and fibronectin either directly or indirectly [20,32]. In this study, we used a computational approach to evaluate 102 major TCM-related natural compounds for an acidic $\mathrm{pH}_{\mathrm{e}}$ environment in human BC.

After evaluation between 102 compounds and $\mathrm{BC}$ cells under an acidic $\mathrm{pH}_{\mathrm{e}}, \mathrm{BD}$ was suggested as the candidate with the most potential to treat $\mathrm{BC}$ against an experimental acidic condition with the highest IG value (IG value: 0.24 ) (Figure 3A and Table S5). BD is a major active quassinoid in Brucea javanica (L.) Merr., which has anti-cancer properties such as anti-proliferative and pro-apoptotic effects via c-Jun N-terminal kinase (JNK), mitogen-activated protein kinases (MAPK), phosphatidylinositol 3-kinase (PI3K)/protein kinase B (AKT)/mammalian target of Rapamycin (mTOR), and canonical Wnt signaling pathways against many cancers including $B C[33,34]$. Our data showed that 10 probes defined as RUD and 24 probes defined as PDU in BC cells were potential therapeutic targets of $\mathrm{BD}$. Moreover, the number of genes defined by PDUs was higher than those defined by RUDs (Figure 3C). This suggests that BD exhibits a pattern to prevent cancer progression by up-regulating the protective genes (NFKBIE, LIFR, SERPINB9, etc.), which were down-regulated due to acidification, rather than down-regulating the risk genes (FAM114A1, PLAC8, SCUBE2, etc.), which were up-regulated due to acidification.

We used the CancerSEA database aimed at identifying the correlation between BD and 14 functional states. The DEGs for BD were evaluated by the IG method, with the highest discrimination powers being against EMT and invasion with an IG score of $>0.1$ (Figure 4A). Our segmented scRNA-seq data originating from $\mathrm{ER}^{+}, \mathrm{HER}^{+}$, and TN BC further supported that higher proportions were seen in cell populations that express positiverelated genes compared to negative-related genes against EMT or invasion (Figure 4B,D). Prior studies have proposed the regulatory effect of BD on EMT, invasion, and apoptosis. BD inhibited STAT3 (Signal Transducer and Activator of Transcription 3) activation that attenuated the cell proliferation, migration, invasion, and stem cell-like properties of osteosarcoma cells [35]. BD dose-dependently increased E-cadherin, whereas BD decreased vimentin and $\beta$-catenin expression that resulted in the reduced migration and invasion abilities of MDA-MB-231 cells [36]. BD increased oxidative stress and inhibited the PI3K/Akt signaling pathway, inducing apoptosis in human pancreatic cancer cells [37]. Interestingly, we found that $\mathrm{BD}$ regulated genes with positive (ANXA2, HSP90B1, TGFBI, $F N 1$ ) and negative (FRK) correlation with EMT, invasion, and metastasis. Overexpressed ANXA2 (Annexin A2) exhibits poor prognosis and correlates positively with invasion and metastasis in BC [38]. Annexin A2 interacts with STAT3 and mediates EGF (Epidermal growth factor) induced EMT [38]. ANXA2 knockdown suppressed $\beta$-catenin expression and inhibited EMT and invasion in ovarian cancer cells [39]. GRP94 (Glucose-regulated protein 94, HSP90B1) expression highly correlates with brain metastatic BC, and autophagy mediated the adaption and survival at metastatic sites [40]. FN1 (Fibronectin 1) is upregulated in various tumors and mediates cell proliferation and migration [41]. FN1 knockdown showed decreased cell migration and invasion by modulating EMT-related proteins such as E-cadherin, N-cadherin, and vimentin in MCF-7 cells [42]. In silico analysis showed that TGFBI (Transforming growth factor beta induced protein) is associated with poor prognosis and aggressive BC subtypes [43]. An in vivo study showed that TGFBI affected hypoxia and metastasis in BC [43]. Previous studies have shown the tumor suppressive role of FRK (Fyn-related kinase) by inhibiting cell proliferation, PTEN (Phosphatase and tensin 
homolog) degradation, and EGF receptor signaling in BC [44-46]. Overexpression of FRK inhibited STAT3 activation, which suppressed the EMT process and cell migration in BC cells [47]. BD treatment may induce ANXA2, TGFI, FN1, HSP90B1 down-regulation, and FRK up-regulation to inhibit tumor metastasis by regulating autophagy, hypoxia, $\beta$-catenin, and STAT3 signaling pathways (Figure 6).

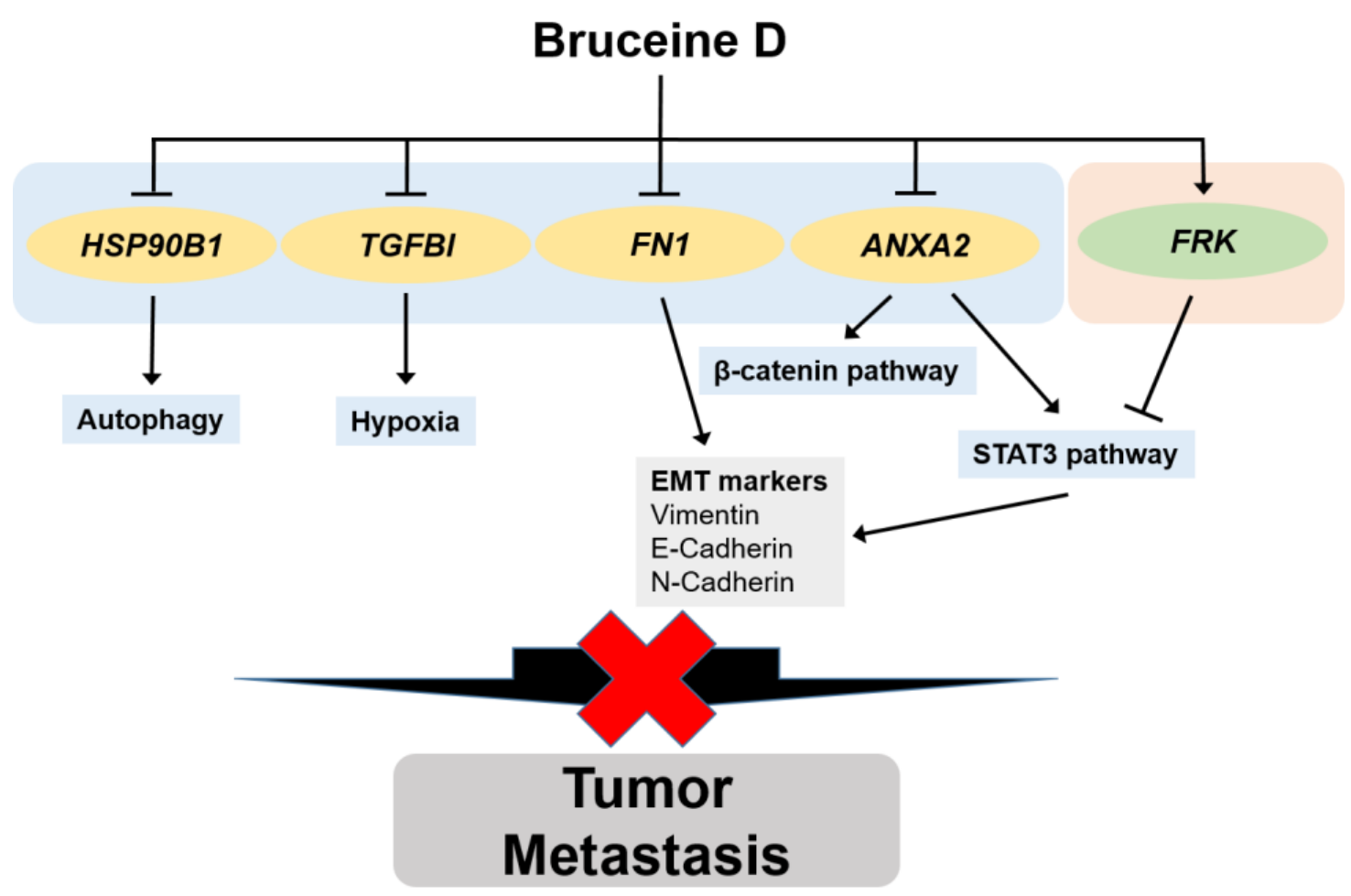

Figure 6. Schematic representation for the inhibitory effect of BD on tumor metastasis.

We next determined whether BD interferes with the tumor cell-TME interactions. The cellular heterogeneity in the TME includes immune cells, fibroblasts, and stromal cells [48]. For this reason, we performed cell-to-cell interaction analysis with single-cell resolution. As a result, among the various ligand-receptor relationships in $\mathrm{ER}^{+} \mathrm{TME}, \mathrm{BD}$ decreased $A P P$ and $C D 44$ expression (Figure 5G). The $A P P$ as a ligand interacted with $C D 74$, which was mainly expressed in $C D 68^{+}$macrophages in the cell-to-cell interaction analysis (Figure $5 \mathrm{C}$ and Figure S6A). APP encodes an amyloid beta precursor protein and is strongly linked to Alzheimer's disease [49]. Interaction between APP and CD74 reduces the production of beta amyloid in Alzheimer's disease [50]. Unfortunately, there is no evidence of a connection between APP and CD74 in cancer. However, APP is up-regulated in BC cells and tissues, which promotes tumor formation and progression $[51,52]$. CD44 is a member of the cell adhesion molecules that have been proposed as having conflicting functions, i.e., either being tumor-promoting or tumor-suppressing in BC [53]. CD44 promotes cancer cell migration and invasion by directly interacting with MMP-9, which degrades collagens [54,55]. CD44 stimulates multidrug resistance protein (P-glycoprotein) expression and leads to chemoresistance in BC cells [56]. Our results demonstrated that CD44 within $\mathrm{ER}^{+}$tumor cells interacted with SPP1, also known as osteopontin (OPN) with macrophages (Figure 5E and Figure S6B). A previous study revealed that the tumor-associated macrophages interacted with $\mathrm{CD} 44^{+}$cancer stem cells and enhanced tumorigenesis via the OPN/CD44 axis [57]. Additionally, OPN induced radiation resistance by activating the CD44 signaling pathway in glioma [58].

In summary, we used in silico methodology to select the most potent compound to target genes characterized by acidic $\mathrm{pH}_{\mathrm{e}}$ that influence the survival of $\mathrm{BC}$ patients. Among the 102 natural compounds, BD showed the highest potential to regulate reprogrammed 
genes driven by acidosis, affecting the prognosis of BC. BD down-regulated genes that positively correlate with EMT and invasion, while it up-regulated genes that negatively correlate with EMT and invasion. BD showed therapeutic potential by changing the TME condition by reducing APP and CD44 expression. Taken together, BD may be an effective natural compound for treating BC metastasis driven by extracellular acidity. More research is needed to fully understand the mechanism of the action of BD in acidic TME.

Supplementary Materials: The following are available online at https:/ / www.mdpi.com/article/ 10.3390/cells10102673/s1, Figure S1: Segmentation of ER+ breast cancer cells from single cell data with patients, Figure S2: Segmentation of HER+ breast cancer cells from single cell data with patients, Figure S3: Segmentation of TN breast cancer cells from single cell data with patients, Figure S4: Heatmap of proportion of positive cells within segmented tumor cells from scRNA-seq with 12 different functional states of cancer cells and gene expression status by BD treated or not, Figure S5: Analysis of normal scRNA-seq data (GSM4909262) which is paired with GSM4909313 ER+ BC, Figure S6: Dot plots of expression of ligands receptor with percent of positively expressed and average of expression in ER+ sample GSM (GSM4909313), Table S1: Total genes for survival analysis with breast cancer patients from TCGA database, Table S2: Total genes for DEG analysis between $\mathrm{pH} 6.5$ and $\mathrm{pH}$ 7.6, Table S3: Significant genes with prognosis and differential expressed between acidic ( $\mathrm{pH}$ 6.5) and normal ( $\mathrm{pH} 7.6)$ condition, Table S4: Significant genes with differential expressed between each compound treated and control group according to acidosis dependent prognosis-related genes, Table S5: Evaluation of effectiveness of compound to acidosis dependent prognosis-related manner, Table S6: Whole significantly differential expressed genes between BD treated and control group.

Author Contributions: Author Contributions: conceptualization, Y.P. and W.K.; investigation, Y.P.; resources, S.S. and W.K.; writing-original draft preparation, Y.P., J.J. and W.K.; writing-review and editing, J.J., S.S. and W.K.; visualization, Y.P.; supervision, W.K.; funding acquisition, W.K. All authors have read and agreed to the published version of the manuscript.

Funding: This research was supported by the Basic Science Research Program through the National Research Foundation of Korea (NRF) funded by the Ministry of Science, ICT \& Future Planning (No. NRF-2018R1C1B6002803).

Institutional Review Board Statement: Not applicable.

Informed Consent Statement: Not applicable.

Data Availability Statement: The datasets presented in this study are available from the corresponding author upon request.

Conflicts of Interest: The authors declare no conflict of interest.

\section{References}

1. Sung, H.; Ferlay, J.; Siegel, R.L.; Laversanne, M.; Soerjomataram, I.; Jemal, A.; Bray, F. Global cancer statistics 2020: Globocan estimates of incidence and mortality worldwide for 36 cancers in 185 countries. CA Cancer J Clin 2021, 71, 209-249. [CrossRef]

2. Haussmann, J.; Corradini, S.; Nestle-Kraemling, C.; Bolke, E.; Njanang, F.J.D.; Tamaskovics, B.; Orth, K.; Ruckhaeberle, E.; Fehm, T.; Mohrmann, S.; et al. Recent advances in radiotherapy of breast cancer. Radiat. Oncol. 2020, 15, 71. [CrossRef]

3. Gote, V.; Nookala, A.R.; Bolla, P.K.; Pal, D. Drug resistance in metastatic breast cancer: Tumor targeted nanomedicine to the rescue. Int. J. Mol. Sci. 2021, 22, 4673. [CrossRef]

4. Riggio, A.I.; Varley, K.E.; Welm, A.L. The lingering mysteries of metastatic recurrence in breast cancer. Br. J. Cancer 2021, 124, 13-26. [CrossRef]

5. Hu, T.; Zhou, R.; Zhao, Y.; Wu, G. Integrin alpha6/akt/erk signaling is essential for human breast cancer resistance to radiotherapy. Sci Rep. 2016, 6, 33376. [CrossRef]

6. Tang, Y.; Wang, Y.; Kiani, M.F.; Wang, B. Classification, treatment strategy, and associated drug resistance in breast cancer. Clin. Breast Cancer 2016, 16, 335-343. [CrossRef] [PubMed]

7. Sonveaux, P.; Copetti, T.; De Saedeleer, C.J.; Vegran, F.; Verrax, J.; Kennedy, K.M.; Moon, E.J.; Dhup, S.; Danhier, P.; Frerart, F.; et al. Targeting the lactate transporter mct1 in endothelial cells inhibits lactate-induced hif-1 activation and tumor angiogenesis. PLoS ONE 2012, 7, e33418. [CrossRef] [PubMed]

8. Warburg, O. On the origin of cancer cells. Science 1956, 123, 309-314. [CrossRef] [PubMed]

9. Gatenby, R.A.; Gillies, R.J. A microenvironmental model of carcinogenesis. Nat. Rev. Cancer 2008, 8, 56-61. [CrossRef] [PubMed]

10. Gatenby, R.A.; Gillies, R.J. Why do cancers have high aerobic glycolysis? Nat. Rev. Cancer 2004, 4, 891-899. [CrossRef] 
11. Damaghi, M.; Wojtkowiak, J.W.; Gillies, R.J. Ph sensing and regulation in cancer. Front. Physiol 2013, 4, 370. [CrossRef]

12. Moellering, R.E.; Black, K.C.; Krishnamurty, C.; Baggett, B.K.; Stafford, P.; Rain, M.; Gatenby, R.A.; Gillies, R.J. Acid treatment of melanoma cells selects for invasive phenotypes. Clin. Exp. Metastasis 2008, 25, 411-425. [CrossRef] [PubMed]

13. Estrella, V.; Chen, T.; Lloyd, M.; Wojtkowiak, J.; Cornnell, H.H.; Ibrahim-Hashim, A.; Bailey, K.; Balagurunathan, Y.; Rothberg, J.M.; Sloane, B.F.; et al. Acidity generated by the tumor microenvironment drives local invasion. Cancer Res. 2013, 73, 1524-1535. [CrossRef] [PubMed]

14. Gatenby, R.A.; Gawlinski, E.T.; Gmitro, A.F.; Kaylor, B.; Gillies, R.J. Acid-mediated tumor invasion: A multidisciplinary study. Cancer Res. 2006, 66, 5216-5223. [CrossRef] [PubMed]

15. Wang, L.; Fan, Z.; Zhang, J.; Changyi, Y.; Huang, C.; Gu, Y.; Xu, Z.; Tang, Z.; Lu, W.; Wei, X.; et al. Evaluating tumor metastatic potential by imaging intratumoral acidosis via ph-activatable near-infrared fluorescent probe. Int J. Cancer 2015, 136, E107-E116. [CrossRef]

16. Thews, O.; Riemann, A. Tumor ph and metastasis: A malignant process beyond hypoxia. Cancer Metastasis Rev. 2019, 38, 113-129. [CrossRef]

17. Tavares-Valente, D.; Baltazar, F.; Moreira, R.; Queiros, O. Cancer cell bioenergetics and ph regulation influence breast cancer cell resistance to paclitaxel and doxorubicin. J. Bioenerg Biomembr 2013, 45, 467-475. [CrossRef]

18. Li, Z.; Zong, L.; Liu, H.; Yao, Z.; Sun, Y.; Li, Z. A solid-state sb/sb2o3 biosensor for the in situ measurement of extracellular acidification associated with the multidrug resistance phenotype in breast cancer cells. Analytical Methods 2018, 10, 4445-4453. [CrossRef]

19. Anemone, A.; Consolino, L.; Conti, L.; Irrera, P.; Hsu, M.Y.; Villano, D.; Dastru, W.; Porporato, P.E.; Cavallo, F.; Longo, D.L. Tumour acidosis evaluated in vivo by mri-cest ph imaging reveals breast cancer metastatic potential. Br. J. Cancer 2021, 124, 207-216. [CrossRef]

20. Luo, H.; Vong, C.T.; Chen, H.; Gao, Y.; Lyu, P.; Qiu, L.; Zhao, M.; Liu, Q.; Cheng, Z.; Zou, J.; et al. Naturally occurring anti-cancer compounds: Shining from chinese herbal medicine. Chin. Med. 2019, 14, 48. [CrossRef]

21. Yao, J.; Czaplinska, D.; Ialchina, R.; Schnipper, J.; Liu, B.; Sandelin, A.; Pedersen, S.F. Cancer cell acid adaptation gene expression response is correlated to tumor-specific tissue expression profiles and patient survival. Cancers (Basel) 2020, 12, 2183. [CrossRef]

22. Lv, C.; Wu, X.; Wang, X.; Su, J.; Zeng, H.; Zhao, J.; Lin, S.; Liu, R.; Li, H.; Li, X.; et al. The gene expression profiles in response to 102 traditional chinese medicine (tcm) components: A general template for research on tcms. Sci Rep. 2017, 7, 352. [CrossRef]

23. Yuan, H.; Yan, M.; Zhang, G.; Liu, W.; Deng, C.; Liao, G.; Xu, L.; Luo, T.; Yan, H.; Long, Z.; et al. Cancersea: A cancer single-cell state atlas. Nucleic Acids Res. 2019, 47, D900-D908. [CrossRef]

24. Pal, B.; Chen, Y.; Vaillant, F.; Capaldo, B.D.; Joyce, R.; Song, X.; Bryant, V.L.; Penington, J.S.; Di Stefano, L.; Tubau Ribera, N.; et al. A single-cell rna expression atlas of normal, preneoplastic and tumorigenic states in the human breast. EMBO J. 2021, 40 , e107333. [CrossRef] [PubMed]

25. Love, M.I.; Huber, W.; Anders, S. Moderated estimation of fold change and dispersion for rna-seq data with deseq2. Genome Biol 2014, 15, 550. [CrossRef] [PubMed]

26. Satija, R.; Farrell, J.A.; Gennert, D.; Schier, A.F.; Regev, A. Spatial reconstruction of single-cell gene expression data. Nat. Biotechnol 2015, 33, 495-502. [CrossRef] [PubMed]

27. Jin, S.; Guerrero-Juarez, C.F.; Zhang, L.; Chang, I.; Ramos, R.; Kuan, C.H.; Myung, P.; Plikus, M.V.; Nie, Q. Inference and analysis of cell-cell communication using cellchat. Nat. Commun 2021, 12, 1088. [CrossRef]

28. Swietach, P.; Vaughan-Jones, R.D.; Harris, A.L.; Hulikova, A. The chemistry, physiology and pathology of ph in cancer. Philos Trans. R Soc. Lond B Biol Sci 2014, 369, 20130099. [CrossRef]

29. Andersen, A.P.; Moreira, J.M.; Pedersen, S.F. Interactions of ion transporters and channels with cancer cell metabolism and the tumour microenvironment. Philos Trans. R Soc. Lond B Biol Sci 2014, 369, 20130098. [CrossRef] [PubMed]

30. Corbet, C.; Feron, O. Tumour acidosis: From the passenger to the driver's seat. Nat. Rev. Cancer 2017, 17, 577-593. [CrossRef]

31. Dong, J. The relationship between traditional chinese medicine and modern medicine. Evid Based Complement. Alternat Med. 2013, 2013, 153148. [CrossRef]

32. Baghban, R.; Roshangar, L.; Jahanban-Esfahlan, R.; Seidi, K.; Ebrahimi-Kalan, A.; Jaymand, M.; Kolahian, S.; Javaheri, T.; Zare, P. Tumor microenvironment complexity and therapeutic implications at a glance. Cell Commun Signal. 2020, 18, 59. [CrossRef]

33. Xu, J.-P. Cancer inhibitors from chinese natural medicines; CRC Press: Boca Raton, FL, USA, 2016.

34. Sin, Z.W.; Bhardwaj, V.; Pandey, A.K.; Garg, M. A brief overview of antitumoral actions of bruceine d. Exploration of Targeted Anti-tumor Therapy 2020, 1, 200-217. [CrossRef]

35. Wang, S.; Hu, H.; Zhong, B.; Shi, D.; Qing, X.; Cheng, C.; Deng, X.; Zhang, Z.; Shao, Z. Bruceine d inhibits tumor growth and stem cell-like traits of osteosarcoma through inhibition of stat3 signaling pathway. Cancer Med. 2019, 8, 7345-7358. [CrossRef]

36. Luo, C.; Wang, Y.; Wei, C.; Chen, Y.; Ji, Z. The anti-migration and anti-invasion effects of bruceine d in human triple-negative breast cancer mda-mb-231 cells. Exp. Ther Med. 2020, 19, 273-279. [CrossRef] [PubMed]

37. Lai, Z.Q.; Ip, S.P.; Liao, H.J.; Lu, Z.; Xie, J.H.; Su, Z.R.; Chen, Y.L.; Xian, Y.F.; Leung, P.S.; Lin, Z.X. Brucein d, a naturally occurring tetracyclic triterpene quassinoid, induces apoptosis in pancreatic cancer through ros-associated pi3k/akt signaling pathway. Front. Pharmacol 2017, 8, 936. [CrossRef]

38. Wang, T.; Yuan, J.; Zhang, J.; Tian, R.; Ji, W.; Zhou, Y.; Yang, Y.; Song, W.; Zhang, F.; Niu, R. Anxa2 binds to stat3 and promotes epithelial to mesenchymal transition in breast cancer cells. Oncotarget 2015, 6, 30975-30992. [CrossRef] [PubMed] 
39. Liu, Y.; Li, H.; Ban, Z.; Nai, M.; Yang, L.; Chen, Y.; Xu, Y. Annexin a2 inhibition suppresses ovarian cancer progression via regulating beta-catenin/emt. Oncol Rep. 2017, 37, 3643-3650. [CrossRef] [PubMed]

40. Santana-Codina, N.; Muixi, L.; Foj, R.; Sanz-Pamplona, R.; Badia-Villanueva, M.; Abramowicz, A.; Marce-Grau, A.; Cosialls, A.M.; Gil, J.; Archilla, I.; et al. Grp94 promotes brain metastasis by engaging pro-survival autophagy. Neuro Oncol 2020, $22,652-664$. [CrossRef] [PubMed]

41. Sun, Y.; Zhao, C.; Ye, Y.; Wang, Z.; He, Y.; Li, Y.; Mao, H. High expression of fibronectin 1 indicates poor prognosis in gastric cancer. Oncol Lett 2020, 19, 93-102. [CrossRef]

42. Yang, X.; Hu, Q.; Hu, L.X.; Lin, X.R.; Liu, J.Q.; Lin, X.; Dinglin, X.X.; Zeng, J.Y.; Hu, H.; Luo, M.L.; et al. Mir-200b regulates epithelial-mesenchymal transition of chemo-resistant breast cancer cells by targeting fn1. Discov Med. 2017, $24,75-85$.

43. Fico, F.; Santamaria-Martinez, A. Tgfbi modulates tumour hypoxia and promotes breast cancer metastasis. Mol. Oncol 2020, 14, 3198-3210. [CrossRef]

44. Meyer, T.; Xu, L.; Chang, J.; Liu, E.T.; Craven, R.J.; Cance, W.G. Breast cancer cell line proliferation blocked by the src-related rak tyrosine kinase. Int J. Cancer 2003, 104, 139-146. [CrossRef]

45. Yim, E.K.; Peng, G.; Dai, H.; Hu, R.; Li, K.; Lu, Y.; Mills, G.B.; Meric-Bernstam, F.; Hennessy, B.T.; Craven, R.J.; et al. Rak functions as a tumor suppressor by regulating pten protein stability and function. Cancer Cell 2009, 15, 304-314. [CrossRef]

46. Jin, L.; Craven, R.J. The rak/frk tyrosine kinase associates with and internalizes the epidermal growth factor receptor. Oncogene 2014, 33, 326-335. [CrossRef]

47. Ogunbolude, Y.; Dai, C.; Bagu, E.T.; Goel, R.K.; Miah, S.; MacAusland-Berg, J.; Ng, C.Y.; Chibbar, R.; Napper, S.; Raptis, L.; et al. Frk inhibits breast cancer cell migration and invasion by suppressing epithelial-mesenchymal transition. Oncotarget 2017, 8, 113034-113065. [CrossRef]

48. Runa, F.; Hamalian, S.; Meade, K.; Shisgal, P.; Gray, P.C.; Kelber, J.A. Tumor microenvironment heterogeneity: Challenges and opportunities. Curr Mol. Biol Rep. 2017, 3, 218-229. [CrossRef]

49. O'Brien, R.J.; Wong, P.C. Amyloid precursor protein processing and alzheimer's disease. Annu Rev. Neurosci 2011, 34, 185-204. [CrossRef]

50. Matsuda, S.; Matsuda, Y.; D'Adamio, L. Cd74 interacts with app and suppresses the production of abeta. Mol. Neurodegener 2009, 4, 41. [CrossRef]

51. Takagi, K.; Ito, S.; Miyazaki, T.; Miki, Y.; Shibahara, Y.; Ishida, T.; Watanabe, M.; Inoue, S.; Sasano, H.; Suzuki, T. Amyloid precursor protein in human breast cancer: An androgen-induced gene associated with cell proliferation. Cancer Sci 2013, 104, 1532-1538. [CrossRef]

52. Lim, S.; Yoo, B.K.; Kim, H.S.; Gilmore, H.L.; Lee, Y.; Lee, H.P.; Kim, S.J.; Letterio, J.; Lee, H.G. Amyloid-beta precursor protein promotes cell proliferation and motility of advanced breast cancer. BMC Cancer 2014, 14, 928. [CrossRef]

53. Louderbough, J.M.; Schroeder, J.A. Understanding the dual nature of cd44 in breast cancer progression. Mol. Cancer Res. 2011, 9 , 1573-1586. [CrossRef] [PubMed]

54. Yu, Q.; Stamenkovic, I. Localization of matrix metalloproteinase 9 to the cell surface provides a mechanism for cd44-mediated tumor invasion. Genes Dev. 1999, 13, 35-48. [CrossRef] [PubMed]

55. Yu, Q.; Stamenkovic, I. Cell surface-localized matrix metalloproteinase-9 proteolytically activates tgf-beta and promotes tumor invasion and angiogenesis. Genes Dev. 2000, 14, 163-176.

56. Bourguignon, L.Y.W.; Xia, W.; Wong, G. Hyaluronan-mediated cd44 interaction with p300 and sirt1 regulates beta-catenin signaling and nfkappab-specific transcription activity leading to mdr1 and bcl-xl gene expression and chemoresistance in breast tumor cells. J. Biol Chem 2009, 284, 2657-2671. [CrossRef]

57. Rao, G.; Du, L.; Chen, Q. Osteopontin, a possible modulator of cancer stem cells and their malignant niche. Oncoimmunology 2013, 2, e24169. [CrossRef]

58. Pietras, A.; Katz, A.M.; Ekstrom, E.J.; Wee, B.; Halliday, J.J.; Pitter, K.L.; Werbeck, J.L.; Amankulor, N.M.; Huse, J.T.; Holland, E.C. Osteopontin-cd44 signaling in the glioma perivascular niche enhances cancer stem cell phenotypes and promotes aggressive tumor growth. Cell Stem Cell 2014, 14, 357-369. [CrossRef] [PubMed] 